\title{
The Design of College Faculty Personnel Information Data Administration System Platform
}

\author{
XIAO Jie CUI Rong Hong REN Zeli \\ Air Force Engineering University, Xi' an, 710038, China
}

\begin{abstract}
The college faculty personnel information data administration (CFPIDA) system platform transforms the personnel information into data, and sets up an impeccable testing \& evaluating mechanism for college faculty. The Dynamic management of faculty information, as well as a complete database, overcomes the low timeliness and low use ratio, and reduces the administration cost.
\end{abstract}

Keywords: College faculty, personnel information, data administration, platform

\section{Introduction}

The testing \& evaluation of college faculty is an important sector in the teaching chain, and depends currently on the human resource information of each individual which reflects individual experiences, performances, rewards and penalties, historical background, and mental and physical behaviors during various events of different life periods [1]. To scientifically establish, administrator and better utilize the personnel information plays a vital role in the exploit of human resource and the promotion of teaching quality. Therefore, the quality of CFPIDA has a direct influence on the teaching contingent construction, personnel reform and the functioning of college personnel work. However, the existing administra- tion methods and approaches are out of date and need a promotion.

\section{Exiting Problems on the Infor- mation Construction of CFPIDA}

(1) Breakpoints on the supervision of teaching quality. Due to the lack of a consistent supervision mechanism and the lack of unified criteria for quantitative assessment, problems would occur from the recruitment of new teachers to the assessment of working ones. Firstly, the teacher procedure isn't well connected to the personnel turnovers. In addition, the assessment criteria consist of some subjective factors.

(2) Outmoded information carrier, poor instantaneity and safety. Currently, most of the university teacher personnel information is still in paper, hence the mode of management, which is far behind the development of our times, severely affects working efficiency. The individual information is incomplete, inaccurate, outdated, and even contradictious to each other. To make problems worse, some are damaged or lost because of fire, flood, earthquake or other causes, and can never be restored [2].

(3) The obsolete management methods. Personnel information management, which is highly political and exclusive, requires specialized qualifications. Working without a computer and specialized software, archives management staffs have a huge working load. Huge quanti- 
ties of new information, such as annual assessment, change in salary, rewards and punishment, further education or training, and the evaluation and employment of professional title etc. [3], are generated annually. Editing traditional archives in paper form, which needs to go through a whole procedure of writing, cutting and pasting, as well as binding, requires the archives management staffs have plenty of patience. It is not only time and energy wasting, but also affects the storage of personnel information. Meanwhile, the growing number of archives and the decreasing capacity for storage, as well as the burden brought by traditional ways to make, use and store archives makes personnel information management very difficult. What's more, some historical archives are gradually aging and demands for advanced technique to restore them.

(4) The low use ratio of personnel information. This is not only the biggest problem existing in the current college faculty personnel information management, but also the main bottleneck in the whole personnel information administration. At work, many departments require the provision of part of the personnel information; as a result, there are lots of retrieval and searching going on. Consequently, manual work with the paper archives is far behind the pace of the development of time which requires instantaneity and accuracy.

\section{The Scheme of CFPIDA System Platform}

In order to solve the problems in university teachers' management, it has become a hot topic of building college faculty personnel information data administration system platform. The nuclear point of the platform is sharing the source of teachers' archives and improving the efficiency in management through digitizing the archives and the management process. It can save, transact, process, searches and transmit the data of kinds of information in daily teaching especially the rich information in research and study to prove more efficient and convenient service [4].

University teacher's information platform is a data management system according to different levels, duties, and years spent teaching to make a dynamic management of university teachers' information, and establish the database, realized the data sharing, resource conservation. Structure diagram is shown in figure 1.

Firstly, Teachers according to the length of data platform dividing into newly introduced teachers and formal mount guard. For the newly introduced teachers build a complete evaluation process, after the inspection qualified to be a formal mount guard. When teachers are introduced, first carries on the learning and training of education basic theory and methods. After training, the school organizes theory examination and teaching assessment for new teachers. Only all subjects pass can the teacher make teaching demonstration. For people who fail to assessment must carry on the basic theory of learning again, and to be a tutor in teaching. The teacher who passes the assessment, in the process of rehearsal, appoint special tutor for help. After a certain time of rehearsal, the university teaching teams conduct selective listening, and make grade evaluation. The teachers whose evaluation results show excellent can mount guard, and to be a formal teacher. The teachers whose evaluation results show well, request help teachers increases the help efforts. Aiming at existing problems, improving tracking frequency of the lectures, supervising the new teachers to improve teaching ability, and the teaching teams review again. For teachers whose evaluation results show poor, to be transferred, transferring teacher jobs. 


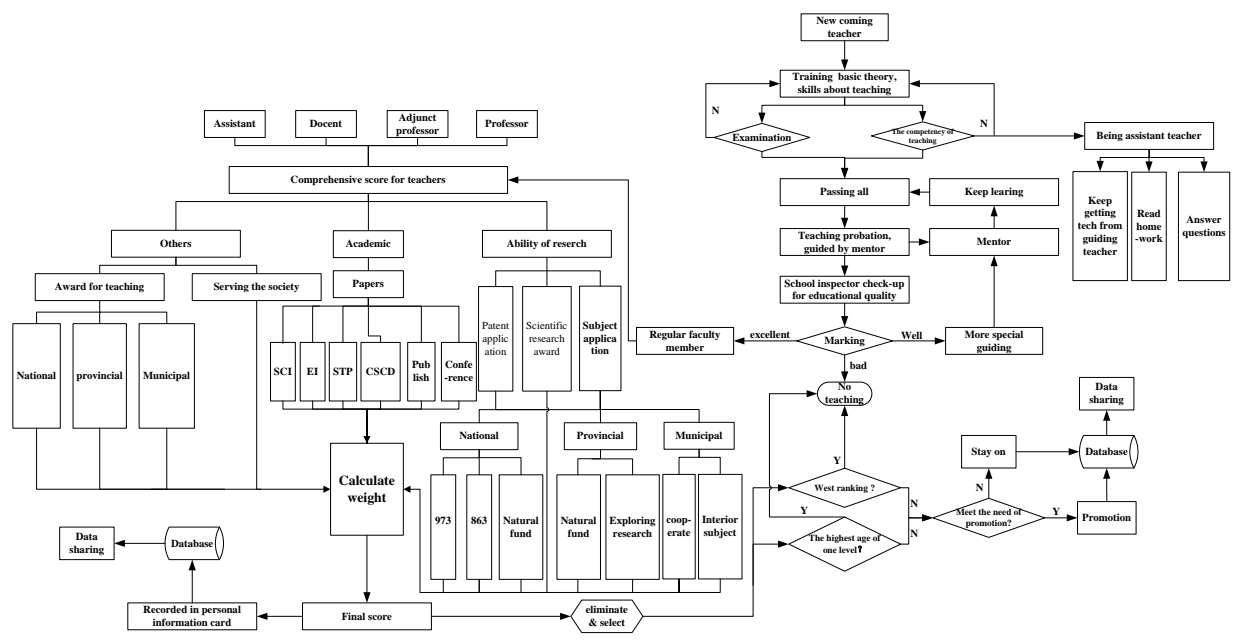

Figure 1. The structure of college faculty personnel information data administration system platform

Secondly, for all the staff, the data management platform established an appraisal system. Carry on the three aspects of comprehensive evaluation for existing university teachers (assistant, instructor, associate professor, professor).

(1) Scientific research ability. Evaluation of university teacher's scientific research ability, mainly according to the teacher's patents number, scientific research award and the patent's application. And scientific research awards can be divided into national (such as 973, 863 and so on), provincial (such as Natural fund, Exploration project and so on) and municipality aggregately three categories. According to the different influence, all the assessment projects has its own weight, so that the digital management of information.

(2) Academic research. University teachers' academic research ability evaluated by data management platform is according to the papers the teacher published. According to the article's impact factor, data management will give different paper different weight index. The result of all paper's normalization is the total score of teachers' academic research.
(3) Other aspects. Mainly refers to the teachers' achievements and serve the society, etc. Teachers' achievement management mainly according to teachers' awards to make decisions. National, provincial, and municipal system will be assigned different weights, to manage the quantitative results. The comprehensive rating of teachers' all the combined quantitative value accounts into digital files of the teachers. Digital files will be included in the database of data management platform, so that the data sharing and management. At the same time, comprehensive score can be transferred to the systems' elimination mechanism, to make personnel's dynamic management. For teachers whose comprehensive rank is at the bottom, the bottom elimination mechanism is implemented, arranging transferring. For teachers who have reached the highest age limit of a level but does not meet the teachers' promotion conditions, have also to be transferred, and included in the system database. For teachers who have neither met the transferring conditions nor the promotion conditions, to stay on and included in the system database. 


\section{Summary}

To achieve teachers' dynamic management of university is the necessary way for university to realize utilization of talent. Data management platform improves the evaluation mechanism of teachers' ability, and realizes the entire link for personnel information from acquisition to dynamic management, solving the problem of poor timeliness and high cost for traditional personnel information management mechanism. Converting teachers' personnel information into the database form, not only is convenient to preserve and manage, but also can realize information resources sharing, making the teachers' ability level and information changing search and inquiry quickly and efficiently.

\section{References}

[1] Chen Huilan. On the Services of University Libraries on Subject Construction [J] Journal of Jiangsu Teachers University of Technology. 2010(5)2930.

[2] Pu Yuhua. To strength the informatization management of personal files of cabres, promoting the innovation of personal management.[J] Reform \& Opening 2011 (09) 102.

[3] Chen Li. The university personal file information management and the development in the informational age.[J] Information \& Technology 2008 (3) 83.

[4] Lu Qi. Research of carde personal archives information management trends. [J] Theoretical Research. 2010 (10) 34. 